\title{
DE ESCRITURAS GLOBALES A PROYECTOS LOCALES: LA HISTORIOGRAFÍA NACIONAL EN EL CONTEXTO DE LA CHILENIZACIÓN DE TARAPACÁ
}

\author{
Global scriptures to local projects: \\ The national historiography in the context of Tarapaca chileanization
}

Germán Morong Reyes*

Eduardo Téllez Lugaro**

\begin{abstract}
RESUMEN
El interés particular de este trabajo es describir dos procesos correlacionados. Un primer nivel de análisis señala la constitución y naturaleza de un relato historiográfico sobre el espacio de frontera norte en el contexto de la chilenización (1883-1929), articulado en forma de una narrativa fundacional siglos XIX y XX. Un segundo nivel trata de poner en evidencia una serie de problemas que, desde una óptica local-regional, han suscitado una preocupación antropológica y sociológica del llamado fenómeno chilenizador, asentando una práctica profesional desde una perspectiva multidisciplinaria; práctica intelectual desarrollada de forma más o menos sistemática desde la década de los setenta en adelante.

Palabras clave: Historiografía nacional, Guerra del Pacífico, chilenización, epistemología, subalternidad, historia local.
\end{abstract}

\footnotetext{
* Departamento de Ciencias Pedagógicas, Facultad de Educación/Centro de Estudios Históricos (CEH)Universidad Bernardo O’Higgins. Santiago, Chile. Correo electrónico: german.morong@ubo.cl

**Centro de Estudios Históricos (CEH), Universidad Bernardo O’Higgins. Santiago, Chile. Correo electrónico: edotellez@gmail.com
}

Artículo recibido el 31 de marzo de 2014. Aceptado el 29 de mayo de 2015. 


\begin{abstract}
The particular interest of this research is to describe two correlated processes. A first level of analysis reveals the constitution and nature of a historiographical account of the north frontier space in the context of the chileanization (1883-1929), structured as a founding narrative s. XIX-XX. A second level attempts to shed light on a series of problems which, from a local-regional perspective, have caused an anthropological and sociological concern for the chileanizing phenomenom, establishing a professional practice from a multidisciplinary perspective; an intellectual practice which has developed systematically from the seventies onwards.
\end{abstract}

Keywords: National historiography, Pacific War, chileanization, epistemology, subalternity, local history.

\title{
PROBLEMATIZACIÓN
}

En las últimas décadas, la Guerra del Pacífico (1879-1883), su proceso y consecuencias, ha suscitado un notable interés historiográfico (McEvoy, 2011, 2012; Cid, 2012, 2013) en función de un renovado análisis de las fuentes y una adscripción metodológica más cercana a la multidisciplinareidad ${ }^{1}$. Es quizás en este tiempo en que más relevancia ha cobrado el concepto de "chilenización" entendido como un proceso sistemático de desperuanización y, a la vez, de imposición de las expresiones, discursivas, materiales y simbólicas, del Estado de Chile en la región de Tarapacá, último norte del territorio. Esta historiografía ha cuestionado sustantivamente los enfoques clásicos, apuntalando la visión estrictamente política, militar y diplomática de las consecuencias del conflicto.

El tránsito de una historiografía nacional, céntrica y homogeneizante, a una instalada en la particularidad local del fenómeno chilenizador ha posibilitado, sin duda, la emergencia de un objeto renovado de estudio; las dinámicas, complejas y subterráneas, que enfrentaron a los agentes del Estado con la población local, adscrita a su vez a complejos procesos de redefinición identitaria (Gundermann, 1998, 2009; Díaz, 2003, 2006; Díaz et al., 2013). El ejercicio concreto de la violencia real y simbólica, por ejemplo, propone una crítica sustantiva al "desinterés" historiográfico positivista de considerar -en sus metarelatos- los procesos histórico sociales situados en una espacialidad distante, y coloca el problema de la cultura subalterna sobre un reclamo epistemológico: la necesidad metodológica de desentenderse de un centro geopolítico -que se instala como marco hermenéutico

\footnotetext{
${ }^{1}$ Nos referimos, específicamente, al diálogo entre antropología, sociología e historia para constituir un objeto de estudio delimitado y espacialmente situado.
} 
objetivo- (Mignolo, 2001, 2003,2005) en la búsqueda legítima de una visibilización histórica de las subjetividades y las conflictividades, cuya lógica puede reconstruirse desde otros registros y tácticas investigativas ${ }^{2}$ (Restrepo, 2007; Chakrabarty, 2000). Con todo, el proceso de chilenización del norte tarapaqueño de las provincias de Tacna y Arica y sus respectivos hinterlands del Pacífico, sugiere una reflexión en torno a la construcción de un campo de conocimiento común cuya genealogía ha transitado entre irrupciones y continuidades epistémicas al interior de la historia, la sociología y la antropología, desde fines del siglo XIX hasta hoy.

En otros términos, pretendemos discutir de manera general y no específica la emergencia de una historiografía nacional que, conjuntamente al interés del Estado de construir chilenidad ${ }^{3}$ a partir de 1883 , constituyó un objeto de estudio cuyo relato se sustentó en procedimientos narrativos destinados a expandir al Estado-Nación e instalar la legitimidad de un consenso social sobre la chilenidad y su ontología fundante. Nos referimos particularmente al discurso histórico decimonónico y de principios del siglo XX, cuya matriz discursiva se relaciona a la reconstrucción de una "historia nacional" en desmedro de un interés por lo regional o local. También, referirnos a las historias militares cuya función fue fortalecer la idea de nación y legitimar su adscripción a ella (McEvoy, 2012). En este sentido, la relación entre historia y nación permite entender un segmento historiográfico cuyas metodologías reconstructivas comulgaron muy fuertemente con el positivismo, privilegiando ciertos niveles de análisis (política, relaciones internacionales, diplomacia, gubernamentalidad, etc.) (Bhabha, 1990:1-7).

En segundo lugar, describir el cambio de perspectiva geopolítica -en términos espistemológicos- que introdujo la antropología y la sociología histórica, que a partir de los ańos 80 puso en el centro de la discusión académica el problema de la etnicidad, la pluriculturalidad y de la subalternidad, anunciando una mirada

\footnotetext{
${ }^{2}$ Tácticas que no reconocen las fronteras nacionales en la constitución de objetos particulares de estudio. Registros que involucran procedimientos sobre una serie de archivos, cuya naturaleza discursiva no está necesariamente circunscrita al documento y que pueden ser rastreados más allá de la noción de frontera política.

${ }^{3}$ Parafraseando al tan citado Foucault, podemos afirmar que la chilenización constituye una gama variada de tecnologías de gobierno, un amplio repertorio de dispositivos de disciplinamiento sobre un conjunto heterogéneo de individuos, constituyentes de una no despreciable pluralidad de adscripciones identitarias. El proceso aludido involucró "prácticas" (actos concretos), oficiales, institucionales, subversivas, populares, con las cuales se extendió territorialmente una supuesta identidad nacional al amparo de un liberalismo modernizador que conllevó la ejecución de dispositivos de control biopolíticos, ideológicos, socioculturales para subalternizar la otredad, inferiorizada a partir de categorías etnoclasificatorias articuladas desde el centro político. (Una de estas categorías, siguiendo a Quijano (2000: 117-131), ha sido la racial; indio, cholo, etc.). Cfr. Foucault, Michel. Seguridad, territorio y población. México: Fondo de Cultura Económica, 2006.
} 
multidisciplinaria desde el "borde" 4 (en sentido real y figurado). Esta periodicidad, en el desarrollo histórico-antropológico, se concibe como un sistema abierto e interrelacionado, una secuencia en proceso y un modelo dinámico y creativo (Restrepo, 2007: 288).

\section{LA HISTORIOGRAFÍA NACIONAL DECIMONÓNICA EN TANTO PRODUCCIÓN GEOPOLÍTICA}

El proceso de reconstrucción narrativa de una historia del Norte Grande estuvo determinado por la confección de una historia nacional. No obstante, el profundo interés por dar cuenta de "hechos" producidos en el norte vinculados a la Guerra o explotación del nitrato produjo una "historia” cuyo lugar de enunciación fue céntrica y miope. El ejercicio de construir una historia oficial entre fines del siglo XIX y las primeras décadas del XX, se desarrolló en función de un tipo de análisis de los archivos, de una gama específica de preguntas a los documentos y de un grado de selectividad de las fuentes consideradas más o menos pertinentes para una historia política, militar y diplomática (McEvoy, 2011). La lógica historiográfica en su explicación de los hechos del Norte Grande era coherente con la expansión del Estado nacional en territorios anexados a la soberanía. La distancia física entre el centro político y el Norte Grande fue también una distancia asumida como cultural con relación al binomio civilización/barbarie y trasparentó, en el relato histórico y literario, la diferencia de lo nacional con lo que está en su externalidad (McEvoy, 2012). En el plano del juego móvil de las identidades colectivas se produce una alteridad conveniente al esfuerzo de definir y empoderar la chilenidad .

Esta historiografía operó ciertas exclusiones que silencian o "inferiorizan" el rol histórico de los sujetos que habitaron los territorios "chilenizados", localizados en el margen como sujetos borrosos y distantes (Galdames, 1998: 79-81). A pesar de que existieron claros intentos de una historia regional en la pluma de funcionarios burocráticos y escritores como Vicente Dagnino, Isaac Arce y Carlos Alfaro ellos no eludieron las lógicas y las palabras autorizadas (Bordieu, 1990) en la constitución de un relato de la chilenidad, siguiendo de cerca los paradigmas nacionales de un Barros Arana, un Amunátegui, un Vicuña Mackenna o un Toribio Medina.

\footnotetext{
${ }^{4}$ Un borde que debe ser repensado. El espacio en cuestión reclama una lógica de análisis propio, presentándose como una unidad cultural (Tacna-Arica y sus hinterlands), como constituyendo un "centro" epistemológico desde donde hablar y pensar lo "nacional", más allá de la frontera política en tanto expresión de la nacionalidad. Esto último nos recuerda una proposición fundamental en los argumentos de los estudios subalternos: que debemos provincializar Santiago de Chile.
} 
El permanente interés de esta primera historiografía fue expurgar los archivos ministeriales, judiciales y burocráticos para fabricar una historia de las formas del dominio. En este sentido, bien poco importaron los mecanismos de resistencia de la población local, los movimientos migratorios de peruanos desplazados hacia el norte o los conflictos locales y variados que implicaban la ocupación militar ${ }^{5}$. Más aún, la población indígena que debiese haber conducido a una reflexión metodológica por parte de la historia, no tuvo clara presencia en el relato clásico. Las implicancias de esta última afirmación son profundas. La discusión sobre la presencia de lo indígena, de la etnicidad y, por ende, de las identidades culturales, no fue materia en el campo de análisis de la clásica historiografía. En la elaboración de la historia nacional, desde mitad del siglo XIX y hasta principios del siglo XX, los indígenas desaparecieron como sujetos históricos para quedar relegados a un pasado glorioso como parte de "nuestras raíces", de los orígenes pero no del presente (Martínez et. al., 2003: 163). En este sentido, la sentencia de Subercaseaux (2003: 69) ha sido elocuente: "en gran medida, lo que hicieron los Estados nacionales y las élites latinoamericanas fue, en lugar de articular y reconocer las diferencias culturales, subordinarlas al centralismo homogeneizador para desintegrarlas". Solo es hasta la década de los 70 cuando el problema de la identidad étnica parece cobrar relevancia.

Puede sostenerse que las claves hermenéuticas para hablar del período transcurrido entre 1883 y 1930 fueron las nociones de chilenidad y territorio nacional. El de la chilenidad implicó la discusión, oficial y popular, de los elementos que la conformaban y, por consiguiente, la apropiación y representación de una identidad chilena en oposición a lo que, social y espacialmente, está fuera de ella (los discursos oficiales, los discursos populares, los saberes cultos e informales, produciendo todo un campo de enunciados clasificadores sobre el juego identidad/ alteridad). Tras la Guerra del Pacífico, la configuración de un nuevo mapa territorial producto de la anexión de Antofagasta y Tarapacá, determinó una nueva forma de conciencia nacional, de adscripción a una identidad chilena sustentada, en su mayor parte, por los discursos institucionales. Desde los distintos organismos estatales se redefinió e impuso una nueva forma de "pensarse" chileno, una nueva representación de la identidad nacional ${ }^{6}$.

\footnotetext{
${ }^{5}$ Un caso sintomático de lo que sostenemos lo constituyen los libros de Gonzalo Bulnes Guerra del Pacífico. De Antofagasta a Tarapacá de 1911 y Guerra del Pacifico (3 volúmenes) de 1955-56. Publicado el primero en Valparaíso y el segundo en Santiago.

${ }^{6}$ Según Sergio Villalobos (2001: XXXVII) "Hubo necesidad de justificar el desarrollo de un destino nacional y fue indispensable crear la imagen de cada país, viniendo a ser la historia la cantera más valiosa y abundante para esa construcción. Se la trabajó, en todos los lugares del continente, con mayor o menor énfasis, transformándose al fin en un espejo para mirar la imagen nacional, dando pie para el análisis frío y razonado, pero también para la contemplación anímica ligada al orgullo de cada nación. Los historiadores, más allá de sus motivos personales, rindieron tributo al ambiente social. Y a la vez influyeron sobre él".
} 


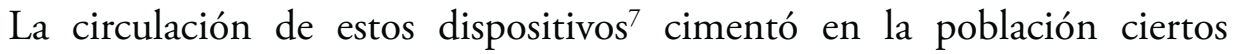
paradigmas acerca del otro peruano sobre la base de un arbitrario proceso etnoclasificatorio constituido, a su vez, en el seno mismo de los discursos liberales y progresistas. Dicho proceso, en tanto constructor de la alteridad, definió ciertos enunciados y saberes fundantes: la homologación de la nacionalidad con la etnicidad, es decir, el peruano como sinónimo de indio, por tanto retrasado e incivilizado, la imagen del "cholo"; un etnónimo (Bromley, 1986) que connota rasgos negativos (cobardía, flojera, suciedad, etc.). En este sentido, la emergencia del "otro" definió una nueva práctica discursiva de clasificación cultural sobre las poblaciones que quedaron más allá de la frontera política (Norte del Valle de Camarones, Arica-Tacna). Estas poblaciones, relegadas a la "externalidad", fueron objeto de la antinomia "civilización" v/s "barbarie", ese otro que, siempre externo, operó como una suerte de espejo negativo para el reflejo de la construcción imaginaria de la nación (Anderson, 1993).

Muy de la mano con lo señalado anteriormente, la presencia de una discursividad sobre el "Territorio nacional" expresó un segundo paradigma del relato histórico de esta primera generación de intelectuales. Las implicancias de un extendido y aceptado discurso sobre la territorialidad chilena determinaron, desde el discurso histórico, el comienzo de la representación de un mapa imaginado de Chile: el trazado posterior de la línea de la Concordia que funcionará como una representación imaginada de la chilenidad. La preocupación por fijar la frontera política se convirtió, en los textos de historia, en una cuestión central:

La anexión territorial desencadenó, entre otros procesos, el desarrollo de un conjunto de estudios destinados a redibujar, para la burocracia nacional, el nuevo espacio territorial de la nación. Podríamos decir que, casi por definición, cada burocracia estatal trata de "dibujar", para sí misma, una determinada representación de los espacios, territorios, poblaciones y riquezas, necesaria para la determinación del control administrativo (Martínez et al., 2003: 199).

Al finalizar el siglo XIX y en pleno proceso de "chilenización”, ya hay una primera reflexión y se ha producido un determinado discurso sobre el espacio de frontera. La versión histórica de Barros Arana y Toribio Medina ha quedado desplazada y un nuevo discurso empezará a desarrollarse, a saber; el de los funcionarios

\footnotetext{
7 Entendemos "dispositivo" en los términos analíticos que nos propone Gilles Deleuze (1990: 155-163), es decir, como un conjunto heterogéneo de prácticas, unos sistemas particulares de enunciación, un régimen específico de verdad articulado sobre discursos, objetos y gestos cuya función, desde la relación saber-poder-subjetividad, es hacer "ver" y hacer "hablar" , ocultar y visibilizar planos de realidad específicos. Se trata de un conjunto variado de tecnologías de fuerza que constituyen subjetividades y que constrińen a el o los sujetos a regímenes de verdad insertos en una historicidad específica.
} 
estatales productores de importantes descripciones, tanto de los territorios como de las poblaciones indígenas y no indígenas que los ocupaban. Eran ingenieros al servicio de Ministerios, tales como el de Obras Públicas y Relaciones Exteriores. Los informes de todos ellos alimentaron por varios años la reflexión de Ministerios del Interior y del Congreso Nacional (Martínez et al., 2003: 200).

Por lo tanto, se pude sostener que los archivos trabajados por las corrientes historiográficas de principios de siglo siguieron la lógica "céntrica" en la constitución de determinados objetos de saber sobre determinados niveles de análisis; política, relaciones exteriores, tratados jurídicos, etc.

\section{ALGUNAS CONSECUENCIAS TEÓRICO-METODOLÓGICAS DE LA TRADICIÓN HISTORIOGRÁFICA CLÁSICA}

La práctica discursiva de este primer corpus historiográfico tuvo, a lo menos, algunas consecuencias epistémico-metodológicas:

a) Se insistió en una historiografía de hechos bélicos y marcadamente nacionalista. Un relato positivista más descriptivo que interpretativo (González Miranda, 1998).

b) No se preguntó sobre el papel de la periferia (un término crecientemente inapropiado) en este tipo de historiografía chilena. Ello ha mostrado que fue necesario reexaminar mucho de la escritura crítica sobre la chilenidad que ha conformado nuestro pensamiento sobre lo sucedido (Cid, 2013: 216-227).

c) Se legitimó un poderoso imaginario de las narrativas que privilegian instituciones modernas como las de "ciudadanía", "nación" o el "sujeto liberal moderno" por encima de otras formas de solidaridad social o experiencias de subjetividad. En general, este privilegio se asocia con un efecto borramiento de la compleja y contradictoria trama de prácticas, relaciones y representaciones al ser subsumidas en una negatividad de la modernidad (Restrepo, 2007: 290).

d) El lugar central del indígena en el proceso aludido fue omitido y en lugar de constituir su emergencia epistémica se homologó su existencia al lugar social de lo salvaje y primitivo, ese otro interno relegado a la externalidad política e histórica (Aguirre y Mondaca, 2011: 5-50). 
e) La práctica historiográfica, por lo menos hasta la década de los años 70, debe ser pensada como una producción geopolítica en vez de ser considerada como un universal discursivo que apela a un efecto de realidad, a un estatuto de verdad. Es decir, a una producción que perfectamente puede ser localizada y provincializada al centro político (Mignolo, 2001, 2003, 2005).

f) Los límites de la "chilenidad" coincidieron con la demarcación de una frontera política en un intento de homologar identidad y prácticas identitarias a la territorialidad política conformada por un impuesto límite fronterizo.

g) Los "pasados subalternos" permanecieron en una exterioridad irreductible al análisis historiográfico que -debido a sus premisas sobre el mundo, el tiempo y los seres- constituyó un principio de inteligibilidad al cual escaparon aquellos pasados en cuanto tales. Solo los redujo a algo "distinto" mediante el despliegue de una violencia epistémica que los hace irreconocibles (Restrepo, 2007: 292).

h) La historiografía nacional dio prioridad al Estado como un ente central en el proceso chilenizador, descuidando el análisis de las prácticas de gobernabilidad. Fue Michel Foucault, en Seguridad, territorio y población (Cursos en el College de France 1977-78), quien hábilmente diferenció entre una analítica del gobierno y una analítica de la gubernamentalidad (Castro-Gómez, 2010: 46). Una teoría del gobierno da por supuesto al Estado como actor unitario, dotado de un conjunto de instituciones o "aparatos" que sirven como asiento y base del gobierno. Una teoría semejante, propia de la historiografía clásica de Chile, se ocupó de reflexionar sobre cuestiones tales como la legitimidad del gobierno, las mejores o peores formas de gobernar (democracia, populismo, totalitarismo), o bien sobre la "sostenibilidad" de las potestades legislativas, punitivas o administrativas del Estado (gobernabilidad, gobernanza, etc.). Por el contrario, una analítica de la gubernamentalidad, que debiese ser analizada para el espacio en cuestión no parte de la unidad del Estado, sino de una multiplicidad de prácticas dotadas de racionalidades particulares (Castro Gómez, 2010: 45-46) ${ }^{8}$.

\footnotetext{
${ }^{8}$ Dirá Foucault: "Las formas y las situaciones específicas del gobierno de unos hombres por otros son múltiples en una sociedad dada, están superpuestas, se cruzan, imponen sus propios límites, algunas veces se destruyen unas a otras, a veces se refuerzan. Es cierto que en las sociedades contemporáneas el Estado no es simplemente una de las formas o situaciones específicas del ejercicio del poder (incluso si es el más importante), sino que en cierta manera todas las otras formas de la relación de poder deben referirse a él. Pero no es porque sean derivadas de él; es más bien porque las relaciones de poder han llegado a estar cada vez más bajo el control del Estado [...] En referencia al sentido restringido de la palabra gobierno, se podría decir que las relaciones de poder han sido progresivamente gubernamentalizadas, es decir, elaboradas, racionalizadas y centralizadas en la forma de, o bajo los auspicios de las instituciones del Estado" (Foucault, 1991: 96).
} 


\section{HACIA UNA HISTORIA LOCAL; LA PUESTA EN ESCENA DE LOS ESPACIOS Y DINÁMICAS SUBALTERNAS}

Solo es a partir de la década de los 70 en que el objeto de estudio, es decir el proceso chilenizador, sufre un desplazamiento significativo en función de un cambio de perspectiva teórico-metodológico. Paulatinamente, comienza a descentrarse la historiografía que apela a lo nacional (si se quiere se desestatiza) y emerge ya en los 80 y 90 lo que podríamos signar como una historia regional, local o microhistoria (Ginzburg, 2000:9-11). Pero no es solo un cambio en la escala de análisis, se trata de imbricar el discurso histórico con los supuestos y preguntas fundamentales de la antropología y la sociología. A partir de los 70, por razones que aquí no compete explicar, la antropología cobra un estatuto de legitimidad básico en el desentrañamiento de los pasados y presentes étnicos de la zona y, consecuentemente, su relación irreversible con la historia conducirá al nacimiento de ese campo de saber hibridizado nominado como etnohistoria (Hidalgo et al., 2013:243-276).

El peregrino estudio de Raúl Palacios (1974) situó el espacio fronterizo en la discusión historiográfica a partir de un nivel categorial acotado: el de la chilenización. En los 80 y 90 se produce una verdadera eclosión de niveles de análisis que privilegian el rol de las subjetividades, el rol de la identidad y sus prácticas de uso móviles y performativas, el tema de la etnicidad y de las comunidades étnicas frente al Estado, las relaciones de dominio violento percibidas por los actores que las vivieron, etc. Los trabajos de Sergio González, Hans Gundermann, Juan Van Kessel, Patricio Tudela, y más recientemente Alberto Díaz, Luis Galdames, Rodrigo Ruz y Carlos Mondaca son prueba del interés por desentrañar el proceso desde "abajo", argumentando reiteradamente la necesidad de concebir el espacio de litigio fronterizo como complejo, móvil y dinámico en las relaciones de los subordinados y las fuerzas externas que los coercionaron. Me parece que la posición que estos autores han tomado sigue de cerca las construcciones epistemológicas de una historia de la cultura (De Certeau, 1993, 1995; Chartier, 1996, 1998), de las contribuciones sobre narrativa y nación que instaló en los 80 el grupo de Estudios Subalternos (Bhaba, 1990; Chakabarty, 2000; Beverley et al., 1998) ${ }^{9}$ y de una

\footnotetext{
${ }^{9}$ Desde esta perspectiva analítica se ha cuestionado el concepto de nación, en función de la contradicción entre el centro, el discurso criollo neocolonial, la exégesis de una historia oficial homogeneizante y la periferia construida desde ese centro. Tal periferia fractura la nación imaginada (Anderson) y reposiciona la territorialidad continua, impuesta por el ideal hegemónico de los Estados independizados por las élites criollas. Es así como se cuestiona el proceso por el cual las naciones fueron asimiladas a nacionalidades estatales, con fines de fijar identidades representadas por los prototipos canónicos del poder. La nación, imaginada e impuesta, ha sido finalmente fracturada por las dicotomías internas de raza, lengua y localidad cultural que eluden las formas interpretativas
} 
antropología histórica muy propia en los 90 que expurgó los documentos desde una perspectiva etnográfica y/o etnológica (Gundermann, 1998, 2009; González, 1995, 1998, 2002, 2004; Díaz et al., 2013).

Entonces, ¿cómo dar cuenta de las "realidades" de esos sujetos locales más allá de la mirada del poder y de la historia nacional? ¿Qué tipo de desplazamiento debió operarse para configurar una historia regional/local, en función de la emergencia de los discursos y las prácticas sociales e individuales de los espacios marginales, que contienen en su interior las representaciones y apropiaciones frente a las políticas chilenizadoras?

Todas estas interrogantes comenzaron lentamente a ser despejadas dada la emergencia de una historiografía regional amparada en estudios de corte sociológico y antropológico. Uno de ellos es el de Sergio González ${ }^{10}$ que, desde el análisis sociológico, ha querido dar cuenta, en palabras de Lautaro Núñez" ${ }^{11}$, "de hechos tan sólidamente documentados que pareciera que en sí mismos estos archivos lo conducen, en este caso, a la revelación del episodio más aterrador que se recuerde de violencia estatal y civil, ejercida sobre la sociedad peruana de la pos guerra salitrera". Por lo mismo, es un segmento gris de una historia regional no incluida en la historias generales y que sería irrepetible y casi incomprensible en las "otras" regiones enmarcadas en el modelo del "Reyno" de Chile" (Núñez, 2005: 99). El autor señala el grado de particularidad del estudio y la pertinencia de este en la

clásicas de la historia y la antropología. La emergencia del desconocimiento de las fronteras nacionales, ha dado paso a situaciones ambiguas de identificación nacional y a considerar, más bien, las fronteras culturales, en las cuales la ciudadanía ha dado paso a la etnicidad y a la historicidad local. La nación debe ser repensada en forma de un kaleidoscopio cultural y racial y no como un producto de procesos de representación de los discursos hegemónicos que imponen, marginan y clasifican. En este proyecto, es vital el tratamiento de nuevas fuentes (las orales) y la reinterpretación y análisis crítico de los documentos escritos que no son, bajo ninguna forma, expresiones de un sólo discurso, sino contienen un concierto polifónico que reclama nuevos instrumentos de análisis.

${ }^{10}$ A comienzos de la década de los 90, Sergio González inició, de alguna manera, la discusión sociológica y las dimensiones regionales y locales del impacto chilenizador después de 1883 y hasta bien entrado el siglo XX. Sus investigaciones pusieron en el centro de atención el problema de la violencia política, civil y étnica sobre las poblaciones locales por parte de los dispositivos de gubernamentalidad chilenos. Con sus trabajos emergió el lugar del "vencido" y sus dinámicas de rearticulación en un espacio territorial aún difuso desde el punto de la nacionalidad política. La trayectoria de sus trabajos más importantes referidos a este tópico es la que sigue; "El poder del símbolo en la chilenización de Tarapacá: Violencia y nacionalismo entre 1907 y 1950", Revista de Ciencias Sociales 5 (1995): 42-56; Chilenizando a Tunupa: La escuela pública en el Tarapacá andino. 1880-1990. Santiago de Chile: Dirección de Bibliotecas, Archivos y Museos, 2002; El Dios cautivo; las Ligas patrióticas en la chilenización compulsiva de Tarapacá (1910-1922). Santiago de Chile: LOM ediciones, 2004; La llave y el candado. Un conflicto entre Perú y Chile por Tacna y Arica (1883 -1929). Santiago de Chile: LOM ediciones, 2008.

${ }^{11}$ Arqueólogo. Premio Nacional de Historia 2002. 
construcción de nuevos sujetos históricos fuera del alcance de la institucionalidad de centro. Quizás la frase más sintomática en función de lo que hemos venido sosteniendo, en la perspectiva de la historia cultural, sea que el autor "se filtró entre los archivos y testimonios vivientes, porque él sabe recorrer todas las metodologías de las ciencias sociales, no como divertimentos teóricos, sino como instrumentos objetivos para revelar reconstrucciones reales con carne y hueso" (Núñez, 2005: 98100). Las conclusiones que se pueden esbozar de este tipo de trabajos adoptan, en realidad, la forma de nuevas preguntas para la investigación histórica. Entre estas, ¿qué debió ocurrir entre los que se quedaron y sus descendientes para construir un nuevo y legítimo país nórtico, inseparable de la nueva nacionalidad chilena y, a su vez, no perdiendo los afectos con la otra ausente? Y en términos metodológicos, ¿cómo abordar procesos de tal envergadura y con tal nivel de secuelas desde la disciplina histórica?

Desde fines de los 90 una joven historiografía del lado peruano y chileno, enunciada como sociohistoria y/o antropología histórica, ha ido reconstruyendo las historias de los sujetos, de las comunidades de Tarapacá durante el siglo XIX y principios del XX. En ella se han ido acotando los espacios territoriales de análisis, como agudizando los enfoques y sus soportes teóricos (Choque, 2012). De una historia general que configuró un "espacio" difuso y homogéneo a partir de privilegiados y selectivos documentos, localizados preferencialmente en el centro, se ha ido construyendo una "sociohistoria", ya habituada a expurgar los archivos regionales y provinciales, conducente a revelar a lo menos dos tipos de procesos: las particularidades microrregionales de las respuestas a la chilenización. Esto es una clara diferenciación del impacto chilenizador en las distintas áreas de la región de Tarapacá (Díaz et al., 2013; Choque 2012) ${ }^{12}$ y, a partir de esa misma diferencia de territorios, la emergencia, en función del proceso de dominio, de diferentes sujetos sociales lo que supone, a buena hora, el análisis de diferentes registros producidos como formas o maneras de aceptación o resistencia a las políticas chilenizadoras. Aquí precisamos la pertinencia de evaluar las propuestas disciplinarias de la historia desde la perspectiva de los estudios de la subalternidad (Beverley et al., 1998).

El abandono sistemático de abordar a las poblaciones de Tarapacá como un todo homogéneo en oposición a la homogeneidad de la supuesta nación chilena, ha conducido a despejar las incógnitas sobre los procesos históricos diferenciados y territorialmente focalizados de las prácticas de dominio y, simultáneamente,

\footnotetext{
${ }_{12}$ Por ejemplo, la histórica diferencia en términos de "frontera cultural" que separan Arica de Iquique, teniendo como nodo o límite el valle de Camarones. Obsérvese, por ejemplo, que la historia del proceso salitrero y la emergencia de la "cuestión social" (propia de la historia social y económica del Norte Grande) no da cuenta con claridad de la provincia de Arica, ella parece estar ausente en la conformación de una historia de la Pampa.
} 
las resistencias de la población local. Los estudios de esta nueva historiografía de Tarapacá manifiestan interés explícito por la constitución de un objeto predilecto; el tema de la comunidad y su relación con el Estado (Gundermann, 1998, 2009). Se refiere esta a colectivos sociales localizados en una territorialidad definida y con mecanismos propios de articulación sociopolítica en contextos históricos definidos, de allí la insistencia por la perspectiva local (Medina, 2009: 123-139). Esta última, esclarecida a partir de un sistemático estudio de los documentos, de la oralidad, de la imagen, del registro material y del conocimiento del territorio que se trata de estudiar $^{13}$.

Uno de los representantes de esta emergente historia regional había señalado los desafíos de futuras investigaciones:

Nos interesa aquí señalar que está pendiente entre los historiadores regionales abordar la problemática desde una orientación socio-histórica, intentando identificar espacios de sociabilidad que ciudadanos peruanos y chilenos debieron asumir en su vida cotidiana, como son la escuela, el reclutamiento militar, las festividades populares y religiosas, el comercio, así como también los lugares de diversión, a partir de la instauración de la nueva frontera norte del territorio chileno (Díaz, 2003: 163-64).

Esta afirmación legitima el interés en desentrańar de qué manera una sociedad juega con los mecanismos de la disciplina a través de procedimientos populares (minúsculos y cotidianos) en lo que Michel de Certaeu (Chartier, 1996: cap. II ) llamó "las maneras de hacer", entendidas como las capacidades populares, diversas y complejas, de apropiarse y "re-presentar" las variadas formas, discursivas o no, ejercidas desde el poder.

${ }^{13}$ Carlos Mondaca (2011: 8) resume esta producción histórico/antropológica más reciente como sigue: Alberto Díaz Araya. "Los Andes de bronce. Conscripción militar de comuneros andinos y el surgimiento de las bandas de bronce en el norte de Chile", Historia 42/2 (2009): 371-399; Alberto Díaz Araya y Claudio Aguirre Munizaga. "El espejismo de los lugares. La construcción del espacio en el desierto tarapaqueño. Huara, siglos XIX-XX", Revista de Geografía Norte Grande 44 (2009): 29-48; Alberto Díaz Araya y Rodrigo Ruz Zagal. "Estado, Escuela Chilena y Población Andina en la ex Subdelegación de Putre. Acciones y Reacciones durante el período post Guerra del Pacífico (1883-1929)", Polis [en línea] 24, 2009; Alberto Díaz Araya y Germán Morong. "El desierto y la miseria. Tributación en el sur peruano. Sibaya 1822", Revista Antropológica XXIV/24 (2006):129-152. Alberto Díaz Araya, Rodrigo Ruz y Carlos Mondaca. "La administración chilena entre los aymara: Resistencia y conflicto en los Andes de Arica (1901-1926)", Revista Antropológica XXII/22 (2004): 215-235. A los que debemos ańadir; Alberto Díaz, Luis Galdames y Rodrigo Ruz. Nación e Identidad en los Andes. Indigenas de Arica y Estado chileno (1883-1929). Arica: Ediciones Universidad de Tarapacá, 2010; Alberto Díaz, Rodrigo Ruz y Luis Galdames. "En los intersticios de la chilenidad. Antonio Mollo y las identidades en conflicto en los Andes. Putre, 1900-1926", Chungara, Revista de Antropología Chilena 45/3 (2013): 473-492. 


\section{ALGUNAS CONSECUENCIAS TEÓRICO-METODOLÓGICAS DE LA PERSPECTIVA LOCAL/REGIONAL}

Los esfuerzos analíticos de esta última generación de investigadores ha tenido algunas consecuencias:

a) Este borde académico va a dar cuenta del problema de las identidades, de sus rupturas, de los mecanismos locales y regionales de recepción a las disposiciones estatales, de las comunidades étnicas y sus estrategias de adscripción o repulsión al poder. Desplaza el objeto de estudio desde el centro político a la "frontera" en una nueva indagación archivística cuya matriz epistémica apunta a construir una historia local y multinacional. Al establecer una noción de identidad acorde con la irrupción y la performatividad, los investigadores siguen de cerca las apreciaciones de los estudios culturales (Hall, 2003: 13-39) ${ }^{14}$.

b) La visibilización de las historias locales a las que les fueron negadas un potencial epistémico; estos lugares (de historia, de memoria, de dolor, de lenguas, de multiculturalidad) ya no son lugares de estudio exclusivamente producidos

\footnotetext{
${ }^{14} \mathrm{El}$ campo de la identidad aparece como un proceso no acabado, en formación, performativo (se apela al término "siendo"), sobre la sólida base de un campo de lo relacional con el otro. Esta presunción asume que los sujetos son socialmente construidos por procesos múltiples que los discursos formalizan y organizan, y que los sujetos constituidos como objetos de discurso también articulan, en forma de representaciones e identificaciones, los contenidos de esos discursos. Así, los procesos de identidad y construcción de esta aparecen, en algunas situaciones, como externas a los sujetos y como desconocidas por estos, en la medida que sobre los individuos no se organiza una "verdad" sino un "poder". En este sentido, Stuart Hall reconoce ciertas características en las cuales se torna más "coherente" el análisis de la(s) identidad(es), a saber: a) No es esencialista, sino estratégico y posicional, b) No señala un núcleo estable del "yo" que se desenvuelve sin cambios a través de la historia, c) Tampoco es (trasladando esta concepción esencializadora al escenario de la identidad cultural) ese "yo" colectivo o verdadero que se oculta dentro de los muchos otros yo más superficiales o artificialmente impuestos, que un pueblo con una historia y una ascendencia compartidas tiene en común y que pueden estabilizar, fijar o garantizar una "unicidad" o pertenencia cultural sin cambios, d) Nunca son singulares, son construidas de múltiples maneras a través de los discursos, prácticas y posiciones diferentes, cruzadas y antagónicas, e) Están sujetas a una historización radical y en constante proceso de cambio y transformación. Las identidades, en consecuencia, se constituyen dentro de la representación y no fuera de ella. En el marco de los procesos de representación de las identidades en los discursos, estas prácticas de subjetivización del otro tendrían, a lo menos, algunas consecuencias: a) Son producidas en ámbitos históricos e institucionales específicos en el interior de formaciones y prácticas discursivas específicas, b) Son un producto de la marcación de la diferencia y la exclusión más que signo de una unidad idéntica y naturalmente constituida, c) Las identidades se construyen a través de la diferencia, no al margen de ella (lo que implica que la identidad sólo se construye a partir del otro, d) Las identidades funcionan como puntos de identificación y adhesión sólo debido a su capacidad de excluir, de omitir, de dejar fuera (acto de poder). Stuart Hall (2003: 13-39).
} 
desde el centro político, sino lugares de pensamiento donde se genera conocimiento sobre su misma historicidad en lo que Mignolo (2003) - para referirse a la relación de Europa/mundo colonial- ha denominado "epistemologías fronterizas".

c) Sobre el trabajo de varios archivos (peruanos, bolivianos y chilenos) se intenta comprender la manera a través de la cual los actores sociales dan sentido a sus prácticas y a sus discursos, las capacidades inventivas de los individuos o de las comunidades y, de otra parte, las presiones, las normas, las convenciones que limitan -de manera más o menos fuerte según las posiciones en las relaciones de dominación- aquello que es posible pensar, enunciar y hacer. Si atendemos a las condiciones de la chilenización impuesta, a los mecanismos y dispositivos discursivos y no discursivos del dominio, se colocó en el centro del trabajo de los historiadores las relaciones complejas y variables, imbricadas entre los modos de organización y de ejercicio del poder político en una sociedad dada y las configuraciones sociales que vuelven posibles esas formas políticas en los espacios y sujetos depositarios del poder.

d) La historia desde los "bordes" territoriales, en este sentido, ha manejado el concepto de representación como la capacidad de las sociedades de "pensar" y "apropiarse" de la diversidad de sentidos, conocimientos y legislaciones que la autoridad emite y cuyo destinatario es el "pueblo". Es así como sobre el terreno de las representaciones del poder político, con Louis Marin (1981, 1993), sobre el terreno de la construcción de las identidades sociales o culturales, con Bronislaw Geremek (1998) y Carlo Ginzburg (2000), se ha definido una historia de las modalidades del "hacer-creer" y las formas de creencia que es, ante todo, una historia de las relaciones de fuerza simbólicas, una historia de la aceptación o del rechazo por parte de los dominados de los principios inculcados, de las identidades impuestas que apuntaban a asegurar y a perpetuar su dominación.

e) Definir la dominación impuesta a las sociedades del espacio de frontera (Tacna-Arica) como una violencia simbólica (González, 1995:42-56), ayuda a comprender cómo la relación de dominación, que es una relación histórica y culturalmente construida, es presentada como una diferencia cultural entre lo que es "chileno" y lo que está fuera de esta comunidad imaginada. Las proposiciones de Louis Marin (1993) acerca del problema de la representación y el poder político, nos hicieron comprender cuál es, en contextos históricos definidos, el poder que tiene la imagen; "efecto-representación en un doble sentido, de personificación de lo ausente -o de lo muerto- y de autorrepresentación que instituye el sujeto de mirada en el afecto y el sentido, la imagen es a la vez instrumentalización de la fuerza, el medio de la potencia y su fundación como poder" (Chartier, 1996: cap. III). El concepto 
de representación manejado por Marin fue un precioso apoyo para que pudieran señalarse y articularse, mejor de lo que permitía la noción de mentalidad, las diversas relaciones que los individuos o los grupos mantienen con el mundo social. En primer lugar, las configuraciones múltiples mediante las cuales se percibe, construye y representa la realidad; a continuación, las prácticas y los signos que apuntan a hacer reconocer una identidad social, a exhibir una manera propia de ser en el mundo, a significar simbólicamente una condición, un rango, la expresión de una autoridad. Por último, y como discusión pertinente al problema de chilenización, las formas institucionalizadas por las cuales "representantes" (individuos singulares o instancias colectivas) encarnan de manera visible, "presentifican", la coherencia de una comunidad, la fuerza de una identidad o la permanencia de un poder.

\section{A MODO DE EPÍLOGO}

Creemos que en la construcción de la historia de este último norte, se ha ido operando gradualmente un desplazamiento de una visión de centro, elemento constitutivo de la historia oficial y/o general, a una multiplicidad de visiones sobre el proceso chilenizador por parte de la disciplina histórica nacional y extranjera; el campo de las representaciones colectivas depositarias del poder político es una de las tantas áreas investigativas que revelan nuevas proximidades con el desarrollo de la microhistoria (Medina, 2009:123-139), como también los estudios que han puesto de relevancia la relación Estado-comunidad, en función de sujetos históricos desplazados por la clásica historiografía: las comunidades indígenas y su articulación con un nuevo Estado, en tanto ente subalternizador. También las posibilidades metodológicas de estudios provenientes de la antropología y la sociología. Su utilización por el trabajo propiamente histórico han permitido una cierta inteligibilidad de procesos que habían quedado relegados al silencio: el ejercicio del poder y la violencia, las representaciones y apropiaciones de la simbología del poder y la emergencia de discursos y estrategias de resistencia.

La ausencia en el macrorrelato hegemónico de problemas sociales y culturales permitió una forma de representación histórica tendiente a crear una imagen colectiva en la "sociedad chilena" sobre la base de la territorialidad, la soberanía y las heroicidades que, en términos de acontecimientos fundantes, construyeron paulatinamente la memoria "oficial" y "popular" del pasado nacional. Las repercusiones sociales de una visión miope, han tenido consecuencias en los ámbitos de la educación. Así, por ejemplo, los textos escolares con los que muchos de nosotros estudiamos historia, se insertaron en un macro-relato hegemónico que homologó la historia de Chile a las fronteras políticas que este fue consolidando a lo largo del siglo XIX en el cual, bajo el ideal de una nación, se homogeneizó 
a la población en una red identitaria llamada "chilenidad", desconociendo los espacios culturales intersticiales que fracturaban, de pronto, la presencia de una clara identidad histórico-nacional.

En esta clásica visión, los espacios de frontera cultural-territorial se presentaron difusos y hasta invisibles, puesto que la frontera política organizó, desde el Estado, la dicotomía entre lo nuestro conocido y lo otro desconocido. Muy por el contrario, los estudios regionales, más arriba descritos, se adhieren a otras lógicas de razonamiento: prefieren ser fieles al desarrollo de una historia regional/local, en la cual las fronteras impuestas desaparecen para dar paso al análisis de lo "particular". En este, la relación de convivencia diaria, en ciertos espacios territoriales, bajo ciertas coyunturas puestas en evidencia, dibuja un mapa en que las tradicionales fronteras políticas casi estáticas (desde el imaginario geopolítico de centro) dan paso a fronteras que se movilizan a lo largo del siglo XIX y principios del XX. Tal movilidad posibilitada por variadas prácticas culturales y constantes asimilaciones identitarias. Un eje de análisis de la historia regional es precisamente la convivencia en un espacio de frontera. Es este intersticio que dibuja la práctica y la emergencia de las discursividades subalternizadas (indios, cholos, mestizos, peruanos y tarapaqueńos), lejos de los procesos de representación académica y de opinión pública, operados desde el centro y articulada en macrorrelatos hegemónicos de poder.

\section{REFERENCIAS}

Anderson, Benedict. Comunidades imaginadas. Reflexiones sobre el origen y la difusión del nacionalismo. México: Fondo de Cultura Económica, 1993.

Aguirre, Claudio y Mondaca, Carlos. "Estado nacional y comunidad andina; Disciplinamiento y articulación social en Arica, 1880-1929”, Historia 44/I (2011): 5-50.

Bhabha, Homi (comp.). Nation and Narration. Londres: Routledge, 1990.

Beverley, John, Oviedo, José y Aronna, Michael. "Manifiesto Inaugural" Grupo Latinoamericano de Estudios Subalternos. En Santiago CastroGómez y Eduardo Mendieta (eds.). Teorías sin disciplina (latinoamericanismo, poscolonialidad y globalización en debate). México: Editorial Miguel Ángel Porrúa, (1998): 17-35. 
Bordieu, Pierre. Sociología y cultura. México: Editorial Grijalbo, 1990.

Bromley, Yuri. Etnografía teórica. Moscú: Editorial Nauka, 1986.

Bulnes, Gonzalo. Guerra del Pacifico. De Antofagasta a Tarapacá. Valparaíso: Sociedad Imprenta y Litografía Universo, 1912.

Bulnes, Gonzalo. Guerra del Pacifico. 3 volúmenes. Santiago de Chile: Editorial del Pacífico, 1955.

Cádiz, Villarroel, Francisco. La “chilenización” en el Norte y Sur de Chile: Una necesaria revisión, Cuadernos Interculturales 11/20 (2013): 11-43.

Castro-Gómez, Santiago. Historia de la gubernamentalidad. Razón de Estado, liberalismo y neoliberalismo en Michel Foucault. Bogotá: Siglo del Hombre Ediciones, 2010.

Chakrabarty, Dipesh. Provincializning Europe. Postocolonial thought and Historical Difference. Princeton: Princeton University Press, 2000.

Chartier, Roger. El mundo como representación. Barcelona: Gedisa, 1998.

Chartier, Roger. Escribir las prácticas. Foucault, de Certeau, Marin. Buenos Aires: Editorial Manantial, 1996.

Choque, Carlos. "Se van los peruanos los más testarudos se quedan: La memoria y olvido de la chilenización en el pueblo de Socoroma”. Tesis doctoral. Perú, Lima: Pontificia Universidad Católica del Perú, 2012.

Cid, Gabriel. "Nacionalizando memorias periféricas: Conmemoraciones y nacionalismo chileno en las regiones de Antofagasta y Tarapacá, 1879-1910", História Unisinos 17/3 (2013): 216-227.

Cid, Gabriel. "La nación bajo examen”, Polis [En línea], 32 (2012). Disponible en: http://polis.revues.org/6603. DOI : 10.4000/polis.6603. [Consultado el 3 de noviembre de 2013].

De Certeau, Michel. La toma de la palabra y otros escritos políticos. México: Universidad Iberoamericana e Instituto Tecnológico y de Estudios Superiores de Occidente, 1995. 
De Certeau, Michel. La escritura de la historia. México: Universidad Iberoamericana, 1993.

De Certeau, Michel. "La operación histórica”. Hacer la historia. Nuevos problemas. Tomo I. Barcelona: Laia, (1985): 3-41.

De Certeau, Michel. "Une épistemologie de transition: Paul Veyne", Annales ESC t. 27. Paris (1972): 1317-1327.

Deleuze, Gilles. “QQué es un dispositivo?” Michel Foucault, filósofo. Barcelona: Gedisa, (1990): 155-163.

Díaz, Alberto. "Aymaras, peruanos y chilenos en los andes ariqueños: Resistencia y conflicto frente a la chilenización del norte de Chile", Revista de Antropología Iberoamericana 1/ 2 (2006): 296-310.

Díaz, Alberto. "La chilenización de Tacna y Arica o los problemas para una historia regional del norte chileno", Revista Werken 4 (2003).

Díaz, Alberto; Ruz, Rodrigo y Galdames, Luis. "En los intersticios de la chilenidad. Antonio Mollo y las identidades en conflicto en los Andes. Putre, 19001926, Chungara, Revista de Antropología Chilena 45/3 (2013): 473-492.

Díaz, Alberto; Galdames, Luis y Ruz, Rodrigo. Nación e identidad en los andes Indigenas de Arica y Estado chileno (1883-1929). Arica: Ediciones Universidad de Tarapacá, 2010.

Díaz, Alberto; Mondaca, Carlos y Ruz, Rodrigo. "Antecedentes político administrativos implementados por el Estado chileno en el área rural de Arica durante 1880-1929”, Revista Percepción 3/4 (1999): 4-20.

Foucault, Michel. Seguridad, territorio y población. México: Fondo de Cultura Económica, 2006.

Foucault, Michel. El sujeto y el poder. Bogotá: Carpe Diem Ediciones, 1991.

Galdames, Luis. "El ámbito de lo "local" como perspectiva de análisis en los pueblos del norte de Chile", Diálogo Andino 18, (1999): 9-19. 
Galdames, Luis. "Los que no cuentan (Escuela Santa María de Iquique 1907)". A 90 años de los sucesos de la Escuela Santa María de Iquique. Pablo Artaza Barrios et al., Santiago de Chile: Centro de investigaciones Diego Barros Arana, Universidad Arturo Prat y LOM ediciones (1998): 79-81.

Galdames, Luis et al. Historia de Arica. Santiago de Chile: Editorial Renacimiento, 1981.

Gazmuri, Cristián. La historiografía chilena (1842-1970). Tomo I. Santiago de Chile: Editorial Taurus, 2006.

Geremek, Bronislaw. La piedad y la horca. Historia de la miseria y de la caridad en Europa. Madrid: Alianza, 1998.

Ginzburg, Carlo. El queso y los gusanos. El cosmos, según un molinero del siglo XVI. Madrid: Editorial Atajos, 2000.

González, Héctor y Gundermann, Hans. "Acceso a la propiedad de la tierra, comunidad e identidades colectivas entre los aymaras del norte de Chile (1821-1930)", Chungara, Revista de Antropología Chilena 41/1 (2009): 51-70.

González, Sergio. La llave y el candado. Un conflicto entre Perú y Chile por Tacna y Arica (1883 -1929). Santiago de Chile: LOM ediciones, 2008.

González, Sergio. El Dios cautivo; las Ligas patrióticas en la chilenización compulsiva de Tarapacá (1910-1922). Santiago de Chile: LOM ediciones, 2004.

González, Sergio. Chilenizando a Tunupa: La escuela pública en el Tarapacá andino. 1880-1990. Santiago de Chile: Dirección de Bibliotecas, Archivos y Museos, 2002.

González, Sergio. De la solidaridad a la xenofobia: Tarapacá 1907-1911”. A 90 años de los sucesos de la Escuela Santa María de Iquique. Pablo Artaza Barrios et al., Santiago de Chile: Centro de investigaciones Diego Barros Arana, Universidad Arturo Prat y LOM ediciones, (1998): 93-118.

González, Sergio. "El poder del símbolo en la chilenización de Tarapacá: Violencia y nacionalismo entre 1907 y 1950", Revista de Ciencias Sociales 5 (1995): 42-56.

Gundermann, Hans. "Comunidades aymaras, identidades colectivas y estados nacionales en los albores del siglo XX". A 90 años de los sucesos de la Escuela 
Santa María de Iquique. Pablo Artaza Barrios et al., Santiago de Chile: Centro de investigaciones Diego Barros Arana, Universidad Arturo Prat y LOM ediciones, (1998): 153-182.

Hall, Stuart et al. "Introducción: ¿Quién necesita identidad?". Cuestiones de identidad cultural. Buenos Aires: Amorrurtu, (2003): 13-39.

Hidalgo, Jorge; Castro, Nelson y Aguilar, Julio. "Historia de los pueblos andinos de Arica, Tarapacá y Atacama. Etnohistoriografía de un programa de investigación, 1971-2012". En Carlos Zanolli; Julia Costilla; Dolores Estruch y Alejandra Ramos (eds.). Los estudios andinos hoy. Práctica intelectual y estrategias de investigación. Rosario: Prohistoria, (2013): 243-276.

Marin, Louis. Des pouvoirs de l'image. Paris: Seuil, 1993.

Marin, Louis. Le Portrait du roi. Paris: Éditions de Minuit, 1981.

Martínez, José Luis; Martínez, Nelson y Gallardo, Viviana. "Rotos, cholos y gauchos: La emergencia de nuevos sujetos en el cambio de algunos imaginarios nacionales republicanos (siglo XIX). En Alejandra Castillo; Eva Muzzopappa; Alicia Salomone; Urrejola, Bernarda y Zapata Claudia (eds.). Santiago de Chile: Ediciones de la Facultad de Filosofía y Humanidades, Universidad de Chile, (2003): 161-190.

McEvoy, Carmen. "Civilización, masculinidad y superioridad racial: Una aproximación al discurso republicano chileno durante la Guerra del Pacífico (1879-1884)", Revista Sociología e Politica 20/42 (2012): 73-92.

McEvoy, Carmen. Guerreros civilizadores. Politica, sociedad y cultura en Chile durante la Guerra del Pacifico. Santiago de Chile: Editorial Universidad Diego Portales, 2011.

Medina, Celso. "Intrahistoria, cotidianidad y localidad", Atenea 500 (2009): 123-139.

Mignolo, Walter. "Cambiando las éticas y las políticas del conocimiento: Lógica de la colonialidad y postcolonialidad imperial”, Tabula Rasa 3 (2005): 47-72.

Mignolo, Walter. Historias locales / diseños globales. Colonialidad, conocimientos subalternos y pensamiento fronterizo. Madrid: Akal, 2003. 
Mignolo, Walter(comp.), Capitalismoy Geopolíticadel Conocimiento: Eleurocentrismo y la filosofía de la liberación en el debate intelectual contemporáneo. Buenos Aires: Ediciones del Signo, 2001.

Núñez, Lautaro. "Reseña” a El Dios Cautivo. Las Ligas Patrióticas en la chilenización compulsiva de Tarapacá (1910-1922)" de Sergio González. Chungara 31/1 (2005): 98-100.

Palacios, Raúl. La chilenización de Tacna y Arica, 1883-1929. Lima: Editorial Arica, 1974.

Podestá, Juan. "Regiones fronterizas y flujos culturales: La peruanidad en una región chilena”, Universum 26/1 (2011): 123-137.

Quijano, Aníbal. “Colonialidad del poder, cultura y conocimiento en América Latina”. En Walter Mignolo (comp.), Capitalismo y geopolitica del conocimiento. El eurocentrismo y la filosofía de la liberación en el debate intelectual contemporáneo. Buenos Aires: Ediciones del Signo (2000): 117-131.

Rabasa, José. "Límites históricos y epistemológicos en los estudios subalternos". En Mabel Moraña (ed.). Nuevas Perspectivas desde/sobre América Latina: El desafio de los Estudios Culturales. Santiago de Chile: Editorial Cuarto Propio, (2000): 107-118.

Restrepo, Eduardo. "Antropología y Colonialidad". En Santiago Castro-Gómez Ramón Grosfoguel (eds.). El Giro Decolonial: Reflexiones para una diversidad epistémica más allá del capitalismo global. Bogotá: Pontificia Universidad Javeriana / Siglo del Hombre Editores, (2007): 289-304.

Subercaseaux, Bernardo. "La construcción de la nación y la cuestión indígena". En Alejandra Castillo; Eva Muzzopappa; Alicia Salomone; Urrejola, Bernarda y Zapata Claudia (eds.), Santiago de Chile: Ediciones de la Facultad de Filosofía y Humanidades, Universidad de Chile, (2003): 57-72.

Téllez, Eduardo. Historia general de la frontera de Chile con Perú y Bolivia. 18251929. Santiago de Chile: Instituto de investigación del patrimonio territorial de Chile-Universidad de Santiago de Chile, 1989.

Villalobos, Sergio. Barros Arana: Formación intelectual de una nación. Santiago de Chile: Editorial Universitaria/Centro de investigaciones Diego Barros Arana, 2001. 
